\title{
The impact of media reports on energy and environmental efficiency in China: evidence from modified dynamic DEA with undesirable outputs
}

\author{
Ying Li ${ }^{1}$,Tai-Yu Linn ${ }^{2}$, Yung-ho Chiu ${ }^{3}$, Huaming Chen ${ }^{4^{*}}$ and Hongyi Cen ${ }^{1}$
}

\begin{abstract}
Background: Rapid economic growth in China has resulted in a commensurate increase in energy consumption, which in turn has seen an increase in environmental pollution problems. Past research has tended to focus on energy and environmental efficiency analyses and has rarely examined the media influence on environmental protection efforts. Further, most studies have used static models and ignored the dynamic changes over time.

Methods: To go some way to filling this research gap, this study developed a modified undesirable Dynamic DEA model that included air quality index (AQI) and $\mathrm{CO}_{2}$ indicators to explore the relationships between energy, the environment, and media report efficiencies in 31 Chinese cities from 2013 to 2016.

Results: It was found that: (1) Chongqing, Guangzhou, Nanjing and Shanghai had efficiencies of 1, but Lanzhou, Shijiazhuang, Taiyuan, Xining and Yinchuan needed significant improvements; (2) Chongqing, Guangzhou, Kunming, Nanning and Shanghai had relatively high media efficiencies, but the other cities had low efficiencies and required improvements; (3) the $\mathrm{CO}_{2}$ emissions efficiencies in most cities were better than the air quality index efficiencies; and 4. the media reports in most cities were found to have a more positive impact on the $\mathrm{CO}_{2}$ emissions efficiency than on the AQI efficiency.

Conclusions: Environmental awareness enhances civilian health and promotes economic growth. Therefore, as the news media should be responsible for promoting environmental protection, they need to increase their environmental pollution coverage. It was found that the environmental pollution media report quality and especially air pollution reports needed improvements, and greater media coverage on environmental pollution and awareness was needed.
\end{abstract}

Keywords: Dynamic DEA, Energy, Efficiency, AQI, $\mathrm{CO}_{2}$, Media report

\section{Background}

The energy required for sustained economic development causes serious carbon dioxide, PM2.5, and sulfur dioxide emissions. The International Energy Agency (IEA) reported that in 2018, global carbon dioxide

*Correspondence: chenhuaming@scu.edu.cn

${ }^{4}$ Sichuan University, Wangjiang Road No. 29, Chengdu 610064, People's Republic of China

Full list of author information is available at the end of the article emissions reached 33,143 million tonnes, a 1.7\% increase over the previous year and the highest growth rate since 2013. Because China's carbon emissions accounted for $27 \%$ of the global total, it has now been the world's largest greenhouse gas emitter for over a decade.

PM2.5 emissions have attracted significant attention. At the 2015 climate change conference, China established three goals in accordance with the Paris Agreement, one of which was a $60-65 \%$ reduction in carbon dioxide original author(s) and the source, provide a link to the Creative Commons licence, and indicate if changes were made. The images or other third party material in this article are included in the article's Creative Commons licence, unless indicated otherwise in a credit line to the material. If material is not included in the article's Creative Commons licence and your intended use is not permitted by statutory regulation or exceeds the permitted use, you will need to obtain permission directly from the copyright holder. To view a copy of this licence, visit http://creativecommons.org/licenses/by/4.0/. The Creative Commons Public Domain Dedication waiver (http://creativeco mmons.org/publicdomain/zero/1.0/) applies to the data made available in this article, unless otherwise stated in a credit line to the data. 
emissions by 2030. In response to these goals, the Chinese government issued commensurate policies, such as the air pollution prevention and control action plan and the Environmental Protection Law, and is implementing national emissions reduction targets.

As the media now has a wide range of access modes, it is followed by many people in China and could be used to encourage a national focus on reducing China's environmental pollution problems.

The association between energy and environmental efficiency has been widely studied $[1,7-10,13,17,26,27$, $29,31,34,35,36-40]$. Some studies have examined the impact of energy efficiency on the overall efficiency of a country or region $[2,5,16-18,34-36]$, and others have explored the relationships between the mass media, air pollution, and environmental issues or awareness $[3,11$, $14,24,25]$, with some particularly focusing on the effects of news media reports that improve the awareness of environmental protection issues [8, 21, 23, 25, 28, 37].

While past studies have examined the relationships between energy and environmental efficiency and between media reports and environmental awareness raising, there have been few discussions looking at the relationships between energy consumption, the environment, and the media. Further, as most studies have tended to employ static energy efficiency and environmental pollution analysis methods, there has been little consideration of dynamic sustainable energy consumption and environmental protection development over time. Therefore, to explore the relationships between energy consumption, media, and environmental efficiencies, this study developed a modified undesirable Dynamic data envelopment analysis (DEA) model that considered the dynamic effects of a carry-over and undesirable output. The air quality index (AQI) was included in the model analysis to more fully consider the relationships between energy consumption and environmental pollution. To avoid the shortcomings in static analysis and to assess the intertemporal influences, carry-over activities were also included in the inputs and outputs.

This paper makes two main contributions. First, in addition to exploring the energy and environmental efficiencies, media release factors were included in the model to comprehensively explore the relationships between energy consumption, the environment, and media communications. Second, to overcome the static analysis problems in previous studies, a dynamic carryover effect was included in the modified undesirable Dynamic DEA model to examine the energy consumption, media, and environmental efficiencies in 31 Chinese cities from 2013 to 2016, with labor, energy consumption, and media reports as the inputs, GDP, $\mathrm{CO}_{2}$, and $\mathrm{AQI}$ as the outputs, and fixed assets as the carry-over.

\section{Literature review}

Past studies on the environment and mass media can be divided into three main categories: (1) energy and air pollution efficiency; (2) energy efficiency impacts on the overall efficiency of a country or region; and (3) the relationship between the mass media, air pollution, and environmental issues.

\section{Energy and air pollution efficiency}

Air pollutant emissions mainly comes from the use of coal and oil-based energy sources. Therefore, environmental efficiency research needs to also focus on energy efficiency. The past studies reviewed in this section tended to focus on the relationships between energy use efficiency and air pollutant emissions in a country or region. For example, $\mathrm{Hu}$ and Wang [9] used a modified DEA model to analyze China's energy efficiency, and found that China's rapid economic development had improved overall energy efficiency, Yeh et al. [40] compared mainland Chinese and Taiwanese energy efficiencies using traditional DEA models, and Song et al. [31] used a Super-SBM model to measure and calculate the energy efficiencies in BRIC countries, finding that while all countries had lower energy efficiencies, they had faster growth trends. In other studies, Wang et al. [34, 35] used a multi-directional efficiency analysis (MEA) method to study regional energy and emissions efficiencies in China, finding that the eastern region was generally more efficient than the central and western regions, and Wang et al. [34, 35] studied $\mathrm{CO}_{2}$ emissions performances, the potential to reduce emissions in China's provinces, and the impact of regulatory policies, finding that the $\mathrm{CO}_{2}$ emissions in the southeastern coastal area provinces were relatively high, and the $\mathrm{CO}_{2}$ emissions in the central and western inland areas were relatively low. Wu et al. [38] used a two-stage network DEA framework to assess Chinas energy conservation and emissions reduction efficiencies during China's eleventh five-year plan (2006-2010), and found that: (1) China's eastern region had the best energy conservation and emissions reduction performances compared to the central and western regions, (2) the central region had better production efficiency than the western region, (3) the western region had more efficient processing than the central region. $\mathrm{Li}$ and $\mathrm{Du}[17]$ analyzed the impact of China's market-oriented reforms on China's energy and carbon emissions efficiency, and found that while the energy use and carbon dioxide emissions performances were poor in most parts of China, the eastern provinces generally performed better than the central and western regions. Meng et al. [26] conducted comprehensive survey studies from 2006 to 2015 that had used DEA models to assess China's EE\&CE (energy and carbon discharge efficiency) 
in 30 provinces or regions from 1995 and 2012, finding that eastern China had the highest EE\&CE, and central China had the lowest. Yao et al. [39] used panel data and a meta-frontier non-radial Malmquist $\mathrm{CO}_{2}$ emissions performance index (MNMCPI) to assess China's provincial industrial sector from 1998 to 2011 and estimate China's $\mathrm{CO}_{2}$ emissions efficiency, finding that the average annual $\mathrm{CO}_{2}$ emissions growth rate in China's provincial industrial sector was 5.53\% from 1998 to 2011. Jebali et al. [13] studied the energy efficiencies in Mediterranean countries from 2009-2012, and found that the they were very high. Abbas et al. [1] reviewed the use of DEA models for energy efficiency development, and Qin et al. [29] used DEA to assess the energy efficiency of China's coastal areas from 2000 to 2012, and found that economic development levels were positively correlated with energy efficiencies, and the Bohai Economic Zone had improved energy efficiency and greater air emissions. In other energy and environmental efficiency studies, Feng et al. (2017) found that China's $\mathrm{CO}_{2}$ emissions were inefficient, $\mathrm{Hu}$ et al. [10] used a congestion total-factor energy efficiency model to analyze the energy efficiencies in 20 Taiwanese administrative regions from 2004 to 2013, and Mehmeti et al. [27] analyzed high temperature fuel cells (HTFC) for power-gas relationships.

\section{Impact of energy efficiency on the overall efficiency of a country or region}

Energy use can promote the development of a country or region. The studies reviewed in this section focus on the impact of energy efficiency on overall and technical efficiencies. Bampatsou et al. [2] used DEA to analyze the technical efficiencies in $15 \mathrm{EU}$ countries from 1980 to 2008, and found that the integration of nuclear energy in the energy mix had had a negative impact, Wang et al. $[34,35]$ extended a directional distance function (DDF) using stochastic front analysis techniques to evaluate the $\mathrm{CO}_{2}$ emissions efficiencies in various Chinese provinces, and found that the southeastern coastal areas had higher $\mathrm{CO}_{2}$ emissions, and Li et al. [16] used a DEA-Malmquist method to analyze the energy intensity in China from 2000 to 2009, finding that China's energy intensity could be reduced based on three internal influencing factors,economic structure, energy consumption structure, and technological progress. In other studies, Lin and Du [17] used a non-radial DDF to explore regional energy and $\mathrm{CO}_{2}$ emissions efficiency in China from 1997 to 2009, and found that China's energy use and $\mathrm{CO}_{2}$ emissions performances were poor, with the eastern provinces generally performing better than the central and western regions, $\mathrm{Li}$ and $\mathrm{Lin}$ [18] proposed a totalfactor energy consumption performance index (TEPI) and used a two-stage double bootstrap approach to measure China's energy efficiency from 1997 to 2012, and found that China's energy technology innovations had a negative impact on TEPI, and Du et al. [5] used DEA to analyze China's $\mathrm{CO}_{2}$ emissions from 2006 to 2012 and conduct a cross-provincial comparison. In more recent studies, Wang et al. [36] using stochastic frontier analysis to analyze China's energy productivity from 1995 to 2012, and concluded that the overall change in energy productivity had been mainly affected by the steady positive and negative technological progress change rates.

\section{Relationship between the mass media, air pollution, and the environment}

The media plays an important role in disseminating information to the public about the health problems associated with air pollution and the severity of environmental pollution to enhance general environmental awareness. This section reviews studies on the relationship between the mass media, air pollution and environmental issues. In an early study, Lowe and Morrison [21] studied the role of the media in popularizing environmental issues, and later McCreery [25] believed that media attention was a predictor of air pollution and was more important than environmental policies, Niklas et al. [28] found that public environmental issues were affected by the number of media reports, and Mayer [24] found that the lack of coherence and specificity of the media possibly undermined the ability of regulators to reform air pollution policy. Mason [23] specifically examined the effectiveness of corporate environmental reporting by 100 companies in promoting social responsibility in groups such as employees and shareholders and outside members such as consumers, Chen [3] analyzed reports from China's official English-language newspaper, the China Daily, on air pollution in China in 2013, and Wang et al. [37] studied Chinese social media to monitor air quality trends and related public perceptions and responses, finding that the information on Weibo reflected the true level of particle pollution. Kay et al. [14] took Sina Weibo as a research object and concluded that it effectively promoted public environmental awareness, Foxwell-Norton and Konkes [8] found that the Australian news media played an important role in protecting coral reefs, and Hswen et al. [11] found that social media could aid in environmental monitoring.

However, in most of these studies, there was little focus on the relationships between the media and AQI and most employed static analyses that did not consider any carry-over effects. Therefore, to address these research gaps, this paper developed a modified Undesirable Dynamic DEA model to explore the energy, media, and environmental efficiencies in 31 Chinese cities. 


\section{Research method}

The dynamic DEA concept was first proposed by Klopp [15] based on Malmquist [22] and then extended by Fare et al. [6]. However, while these models measured changes in intertemporal efficiency, they did not consider the effects of the intertemporal continuation activities and therefore, were less suitable for measuring longterm efficiencies. Tone and Tsutsui [32] then included a carry-over and extended the slacks-based measure model (SBM) to a dynamic analysis. The model description is as follows (without undesirable variable),

Suppose the observation is a $J(J=1 \ldots n)$ dimension decision making unit (DMU) set in which the DMU under evaluation is represented by $D M U_{O}$ and subject to $D M U_{O} \in J$, with inputs and outputs used to compute the efficiency labeled $\mathrm{m}$ inputs $x_{i j t}(\mathrm{i}=1 \ldots \mathrm{m})$ and $\mathrm{s}$ outputs $\mathrm{Y}_{l j t}$ with $Z^{\text {good }}$ carried over from period $\mathrm{t}$ to period $\mathrm{t}+1$. The following is the non-oriented model:

$$
\theta_{0}^{*}=\min \frac{\frac{1}{T} \sum_{t=1}^{T} W^{t}\left[1-\frac{1}{m+\text { ninput }}\left[\sum_{i=1}^{m} \frac{s_{i t}^{-}}{x_{\text {iot }}}+\sum_{r=1}^{\text {nbad }} \frac{s_{r t \text { in }}^{\text {input }}}{\text { trot }_{\text {rot }}}\right]\right]}{\frac{1}{T} \sum_{t=1}^{T} W^{t}\left[1+\frac{1}{s_{1}}\left[\sum_{l=1}^{s_{1}} \frac{s_{j t}^{+g}}{y_{\text {lot }}^{g}}\right]\right]}
$$

Equation (1) is the connection equation between $t$ and $\mathrm{t}+1$.

$$
\begin{aligned}
& \sum_{j=1}^{\mathrm{n}} \mathrm{z}_{\mathrm{ijt}}^{\alpha} \lambda_{\mathrm{j}}^{\mathrm{t}}=\sum_{\mathrm{j}=1}^{\mathrm{n}} \mathrm{z}_{\mathrm{ijt}}^{\alpha} \lambda_{\mathrm{j}}^{\mathrm{t}+1}(\forall \mathrm{i} ; \mathrm{t}=1, \ldots, \mathrm{T}-1), \\
& \mathrm{x}_{\mathrm{iot}}=\sum_{j=1}^{n} \lambda_{i}^{t}+s_{i t}^{-}(\mathrm{i}=1, \ldots, \mathrm{m} ; \mathrm{t}=1, \ldots, \mathrm{T}), \\
& \mathrm{y}_{\text {lot }}=\sum_{\mathrm{j}=1}^{\mathrm{n}} y_{l j t}^{+g} \lambda_{\mathrm{j}}^{\mathrm{t}}-\mathrm{s}_{\mathrm{lt}}^{+}(\mathrm{l}=1, \ldots, \mathrm{s} 1 ; \mathrm{t}=1, \ldots, \mathrm{T}), \\
& \mathrm{Z}_{\mathrm{rot}}^{\text {input }}=\sum_{\mathrm{j}=1}^{\mathrm{n}} \mathrm{z}_{\mathrm{rit}}^{\text {input }} \lambda_{\mathrm{j}}^{\mathrm{t}}+\mathrm{s}_{\mathrm{rt}}^{\text {input }}(\mathrm{r}=1, \ldots, \operatorname{ninput} ; \mathrm{t}=1, \ldots, \mathrm{T}),
\end{aligned}
$$$$
\sum_{j=1}^{n} \lambda_{j}^{t}=1(t=1, \ldots, T),
$$$$
\lambda_{j}^{t} \geq 0, s_{i t}^{-} \geq 0, s_{l t}^{+} \geq 0 .
$$

The most efficient solution is:

$$
\theta_{0}^{*}=\min \frac{\left[1-\frac{1}{m+\text { ninput }}\left[\sum_{i=1}^{m} \frac{s_{i t}^{-}}{x_{\text {iot }}}+\sum_{r=1}^{\text {nbad }} \frac{s_{r t}^{\text {input }}}{z_{\text {rot }}^{\text {irput }}}\right]\right]}{1+\frac{1}{s_{1}}\left[\sum_{l=1}^{s_{1}} \frac{s_{j t}^{+g}}{y_{\text {lot }}^{g}}\right]}
$$

\section{Modified undesirable dynamic SBM model}

However, the above model does not consider undesirable outputs. As this study used panel data from 31 of the most developed cities across China, it was assumed that there was a consistent and homogenous balance. Six variables were employed: three inputs; employees, energy consumption and media reports; three outputs; GDP (desirable) $\mathrm{CO}_{2}$ (undesirable) and AQI (undesirable); and one carry-over; fixed assets.

The reduction of $\mathrm{CO}_{2}$ emissions is one of the most important tasks in the global climate change. At the climate conference, all countries pledged to control carbon dioxide emissions within a certain range. Therefore, the $\mathrm{CO}_{2}$ emissions in this study are undesirable output. AQI is the Air Quality Index. AQI describes the degree of air cleanliness or pollution, and is a new air quality evaluation standard issued by China in March 2012. There are six pollutant monitoring items: sulfur dioxide, nitrogen dioxide, PM10, PM2.5, carbon monoxide and ozone. The data is updated every hour. AQI presents the pollution degree of these 6 pollutants by using a unified evaluation standard. Therefore, this study regards AQI as an undesirable output. $\mathrm{CO}_{2}$ and $\mathrm{AQI}$ have a bad effect on production and both $\mathrm{CO}_{2}$ and AQI are Non Separable bad output.

Because the undesirable outputs $\left(\mathrm{CO}_{2}\right.$ and $\left.\mathrm{AQI}\right)$ are considered in the dynamic SBM model, Tone and Tsutsui's [32] dynamic SBM model was modified to include undesirable output.

The observation was a $J(J=1 \ldots . \mathrm{n})$ dimension decision making unit (DMU) set in which the DMU under evaluation was represented by $D M U_{o}$ and subject to $D M U_{o} \in \mathrm{J}$. The inputs and outputs used to compute the efficiency were labeled as $\mathrm{m}$ inputs $x_{i j t}(\mathrm{i}=1 \ldots \mathrm{m})$ and s outputs $Y_{l j t}$. Output $\mathrm{Y}$ was divided into $\left(\mathrm{Y}^{\mathrm{g}}, \mathrm{Y}^{\mathrm{b}}\right)$, where $\mathrm{Y}^{\mathrm{g}}$ was the desirable output, $\mathrm{Y}^{\mathrm{b}}$ was the undesirable output, and $z^{i n-}$ ${ }^{p u t}$ was the carryover from period $\mathrm{t}$ to period $\mathrm{t}+1$. The following is the developed non-oriented model:

$$
\theta_{\mathrm{o}}^{t}=\min \frac{\frac{1}{T} \sum_{t=1}^{T} W^{t}\left[1-\frac{1}{m+\text { ninput }}\left[\sum_{i=1}^{m} \frac{s_{i t}^{-}}{x_{\text {iot }}}+\sum_{r=1}^{\text {nbad }} \frac{s_{r t}^{\text {input }}}{\text { rinut }_{\text {inpt }}}\right]\right]}{\frac{1}{T} \sum_{t=1}^{T} W^{t}\left[1+\frac{1}{s_{1}}\left[\sum_{l=1}^{s_{1}} \frac{s_{i t}^{+g}}{y_{\text {lot }}^{+g}}+\sum_{l=1}^{s_{1}} \frac{s_{j t}^{-b}}{y_{l o t}^{b}}\right]\right]}
$$


Equation (4) was the connection equation between $t$ and $\mathrm{t}+1$.

$$
\begin{aligned}
& \sum_{j=1}^{\mathrm{n}} \mathrm{z}_{\mathrm{ijt}}^{\alpha} \lambda_{\mathrm{j}}^{\mathrm{t}}=\sum_{\mathrm{j}=1}^{\mathrm{n}} \mathrm{z}_{\mathrm{ijt}}^{\alpha} \lambda_{\mathrm{j}}^{\mathrm{t}+1}(\forall \mathrm{i} ; \mathrm{t}=1, \ldots, \mathrm{T}-1), \\
& \mathrm{x}_{\mathrm{iot}}=\sum_{i=1}^{m} \lambda_{i}^{t}+s_{i t}^{-}(\mathrm{i}=1, \ldots, \mathrm{m} ; \mathrm{t}=1, \ldots, \mathrm{T}), \\
& \mathrm{y}_{\text {lot }}=\sum_{\mathrm{l}=1}^{\mathrm{s} 1} y_{\text {lot }}^{+g} \lambda_{\mathrm{j}}^{\mathrm{t}}-\mathrm{s}_{\mathrm{lt}}^{+\mathrm{g}}(\mathrm{l}=1, \ldots, \mathrm{s} 1 ; \mathrm{t}=1, \ldots, \mathrm{T}), \\
& \mathrm{y}_{\mathrm{lot}}=\sum_{\mathrm{l}=1}^{\mathrm{s} 2} y_{\text {lot }}^{-b} \lambda_{\mathrm{j}}^{\mathrm{t}}+\mathrm{s}_{\mathrm{lt}}^{-b}(\mathrm{l}=1, \ldots, \mathrm{s} 2 ; \mathrm{t}=1, \ldots, \mathrm{T}), \\
& \mathrm{z}_{\mathrm{rot}}^{\mathrm{input}}=\sum_{\mathrm{r}=1}^{\mathrm{n}} \mathrm{z}_{\mathrm{rit}}^{\mathrm{input}} \lambda_{\mathrm{j}}^{\mathrm{t}}+\mathrm{s}_{\mathrm{rt}}^{\mathrm{input}}(\mathrm{r}=1, \ldots, \mathrm{ninput} ; \mathrm{t}=1, \ldots, \mathrm{T}), \\
& \mathrm{n} \lambda_{\mathrm{j}=1}^{\mathrm{t}}=1(\mathrm{t}=1, \ldots, \mathrm{T}), \\
& \lambda_{\mathrm{j}}^{\mathrm{t}} \geq 0, \mathrm{~s}_{\mathrm{it}}^{-} \geq 0, \mathrm{~s}_{\mathrm{lt}}^{+\mathrm{g}} \geq 0,, \mathrm{~s}_{\mathrm{lt}}^{-b} \geq 0, \mathrm{~s}_{\mathrm{rt}}^{\text {good }} \geq 0 .
\end{aligned}
$$

The most efficient solution, therefore, is:

$$
\rho_{0 \mathrm{t}}=\frac{1-\frac{1}{m+n i n p u t}\left[\sum_{i=1}^{m} \frac{s_{i t}^{-}}{x_{i o t}}+\sum_{r=1}^{n b a d} \frac{s_{r t}^{\text {input }}}{z_{\text {rot }}^{\text {nput }}}\right]}{1+\frac{1}{s_{1}}\left[\sum_{l=1}^{s_{1}} \frac{s_{j t}^{+g}}{y_{\text {lot }}^{g}}+\sum_{l=1}^{s_{1}} \frac{s_{j t}^{-b}}{y_{l o t}^{b}}\right]}(\mathrm{i}=1, \ldots, \mathrm{T}) .
$$

\section{Labor, energy consumption, media report, GDP, $\mathrm{CO}_{2}$ and AQI efficiencies}

$\mathrm{Hu}$ and Wang's (2006) total-factor energy efficiency index was employed to overcome any possible bias in the traditional energy efficiency indicators. There were six key variables in this study: labor, energy consumption, media reports, GDP, $\mathrm{CO}_{2}$, and AQI, with "I" representing area and " $\mathrm{t}$ " representing time.

The six efficiency models were therefore defined as follows:

$$
\text { Labor efficiency }=\frac{\text { Target Labor input }(i, t)}{\text { Actual Labor input }(i, t)}
$$

$$
\text { Energy consumption efficiency }=\frac{\text { Target Energy input }(\mathrm{i}, \mathrm{t})}{\text { Actual energy input }(\mathrm{i}, \mathrm{t})}
$$

$$
\begin{aligned}
& \text { Media efficiency }=\frac{\text { Target media input }(\mathrm{i}, \mathrm{t})}{\text { Actual media input }(\mathrm{i}, \mathrm{t})} \\
& \text { GDP efficiency }=\frac{\text { Actual GDP desirable output }(\mathrm{i}, \mathrm{t})}{\text { Target GDP desirable output }(\mathrm{i}, \mathrm{t})}
\end{aligned}
$$

$\mathrm{CO}_{2}$ efficiency $=\frac{\text { Target } \mathrm{CO} 2 \text { undesirable output }(\mathrm{i}, \mathrm{t})}{\text { Actual } \mathrm{CO} 2 \text { undesirable output }(\mathrm{i}, \mathrm{t})}$

AQI efficiency $=\frac{\text { Target AQI undesirable output }(\mathrm{i}, \mathrm{t})}{\text { Actual AQI undesirable output }(\mathrm{i}, \mathrm{t})}$

If the target labor, energy consumption, and media input equaled the actual input, then the labor, energy consumption and media efficiencies were 1 , indicating overall efficiency. If the target labor, energy consumption, and media input were less than the actual input, then the labor, energy consumption, and media efficiencies were less than 1 , indicating overall inefficiency.

If the target GDP desirable output was equal to the actual GDP desirable output, then the GDP efficiency was 1 , indicating overall efficiency. If the actual GDP desirable output was less than the target GDP desirable output, then the GDP efficiency was less than 1, indicating overall inefficiency.

If the target undesirable $\mathrm{CO}_{2}$ and $\mathrm{AQI}$ output efficiencies were equal to the actual undesirable $\mathrm{CO}_{2}$ and $\mathrm{AQI}$ output efficiencies, then the $\mathrm{CO}_{2}$ and AQI efficiencies equaled 1 , and were efficient. If the target $\mathrm{CO}_{2}$ and $\mathrm{AQI}$ undesirable output efficiencies were less than the actual $\mathrm{CO}_{2}$ and AQI undesirable outputs, then the $\mathrm{CO}_{2}$ and $\mathrm{AQI}$ efficiencies were less than 1 , indicating inefficiency.

\section{Empirical study}

\section{Data sources}

2013 to 2016 panel data from 31 of the most developed cities from eastern to western China were extracted from the Statistical Yearbooks of China, the Demographics and Employment Statistical Yearbooks of China, and each city's Statistical Yearbooks. The air pollutant data were collected from the China Environmental and Protection Bureau Annual Reports and the China Environmental Statistical Yearbook.

As the 31 cities vary in population, industrial aggregation, natural resources, meteorological conditions, and geography, as a whole they represented the general air pollution emissions and treatment situation in China. As in past research on energy and the environment, the inputs were labor, energy consumption, fixed assets, and media reports [5, 16, 35], and the outputs were GDP as the desirable output, and $\mathrm{CO}_{2}$ and $\mathrm{AQI}$ as 


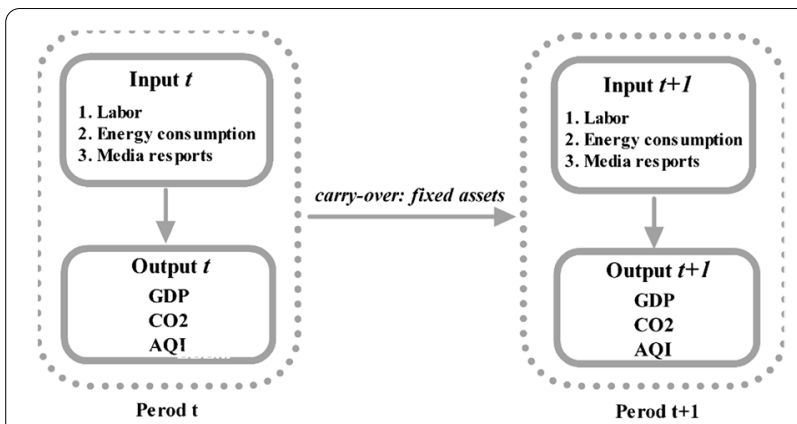

Fig. 1 Efficiency analysis for economic growth, carbon emissions and air pollutant emissions under the influence of news media

Table 1 Input and output variables

\begin{tabular}{lll}
\hline Input variables & Output variables & Carry over \\
\hline Labor & $\mathrm{GDP}$ & Fixed assets \\
Energy consumption & $\mathrm{CO}_{2}$ & \\
Media reports & $\mathrm{AQI}$ & \\
\hline
\end{tabular}

the undesirable outputs. Past studies have included $\mathrm{CO}_{2}$ emissions and ignored AQI indicators [12, 30], however, as China regarded the Air Pollution Control Action Plan as one of its economic development considerations in 2013, only including $\mathrm{CO}_{2}$ as the undesirable output and ignoring other undesirable air pollutants such as $\mathrm{PM}_{2.5}$, $\mathrm{SO}_{2}$, and $\mathrm{NO}_{2}$ could lead to biased reports and poor policy recommendations. Therefore, as in several previous studies, both $\mathrm{CO}_{2}$ and the AQI air pollution indicators are included in the model analysis $[4,19,20,33-35,40]$. This study deferred the production process through fixed assets to the second phase, and analyzed the efficiency of economic growth (GDP), carbon emissions $\left(\mathrm{CO}_{2}\right)$ and air pollutant emissions (AQI) as well as accounting for the news media input, as shown in Fig. 1.

The variables using in this study are explained in Table 1 and defined as follows.

\section{Input variables}

Labor input: unit=people; the number of employees in each city at the end of each year.

Energy consumption: unit $=100$ million tonnes; the total energy consumption in each city each year.

Media reports: news or press releases related to "province + air pollution", which were extracted from The People's Daily and Xinhuanet Media's official website.

\section{Output variables}

Desirable output index GDP in each city; unit $=100$ million $\mathrm{CNY}$.
Undesirable output index $\mathrm{CO}_{2}$ and Air quality Index (AQI), which was the measured concentration of air pollutants ad incorporated particulate matter $\left(\mathrm{PM}_{2.5}, \mathrm{PM}_{10}\right)$, sulfur dioxide $\left(\mathrm{SO}_{2}\right)$ and Nitrogen.

Carry over index Fixed assets: unit: 100 million CNY, which was measured as the capital stock in each city at the end of each year.

\section{Statistical analysis}

Figure 2 shows the overall labor, fixed assets investment, energy consumption input and GDP output indicators from the 31 cities in China from 2013 to 2016. It can be seen that there was substantial growth in both the fixed assets and GDP inputs, with rises also being seen also in the maximum, average, and minimum values. The labor minimum, maximum, and average values rose slightly, which may have been related to the decline in population growth in China during this period. The maximum energy consumption fell to its lowest level in 2014 and then rebounded to its highest level in 2016; however, the average and minimum values continued to decline.

Figure 3 shows the changes in the number of associated news media reports, $\mathrm{CO}_{2}$ emissions and the $\mathrm{AQI}$ from 2013 to 2016, from which it can be seen that the news media reports' maximum, minimum and average dropped significantly, with the maximum reaching its highest level in 2013 and its lowest level in 2016, and with the average and minimum values showing the same trends. Reports on air pollution decreased, which may also reflect the public's lower concerns about air pollution. The maximum $\mathrm{CO}_{2}$ emissions rose slightly, the minimum and average values decreased slightly, and the gap between the maximum and minimum widened.

\section{Results}

\section{Overall efficiency}

As can be seen in Table 2, from 2013 to 2016, the average efficiencies in the 31 cities varied, with most cities needing improvements. The overall efficiency was 1 in Chongqing, Guangzhou, Nanjing and Shanghai, and Beijing's efficiency was high in the first three years, but by 2016 had fallen to 0.6572 . The total efficiencies in Changsha, Guiyang, Haikou, Hangzhou, Hefei, Huhehot, Lhasa, Nanchang, Shenyang, Tianjin, Wuhan, Urumqi and Zhengzhou ranged from 0.4 to 0.7 , and in Lanzhou, Shijiazhuang, Taiyuan, Xining and Yinchuan were the worst, with the highest efficiency not exceeding 0.4.

The overall efficiencies in Jinan, Kunming, Nanjing, and Shenyang increased, with the largest increase being in Jinan from around 0.4 in 2013 and 2014 to 1 in 2016, and the largest fall in efficiency being in Beijing. The 

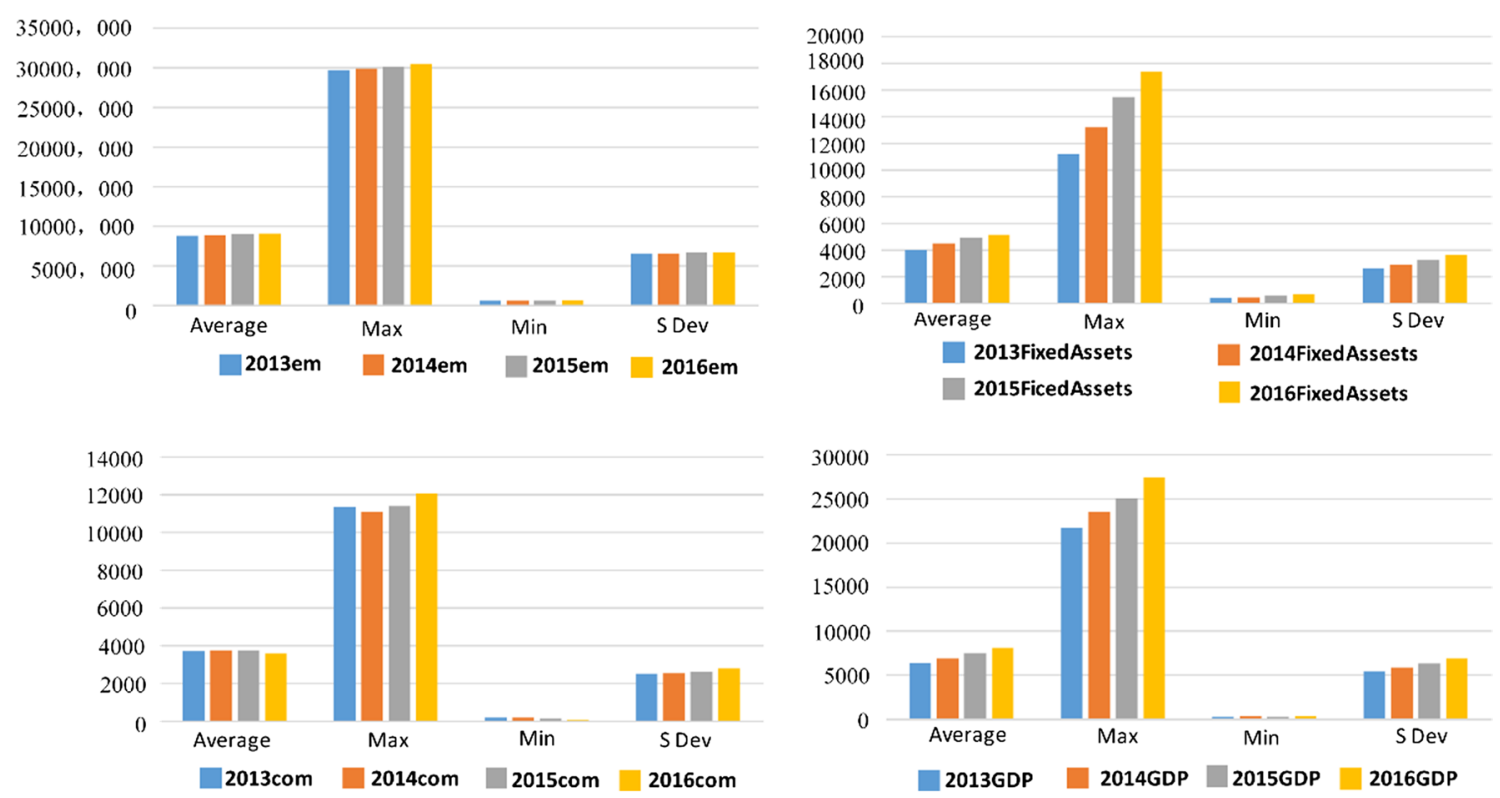

Fig. 2 Labor, fixed assets, energy consumption and GDP

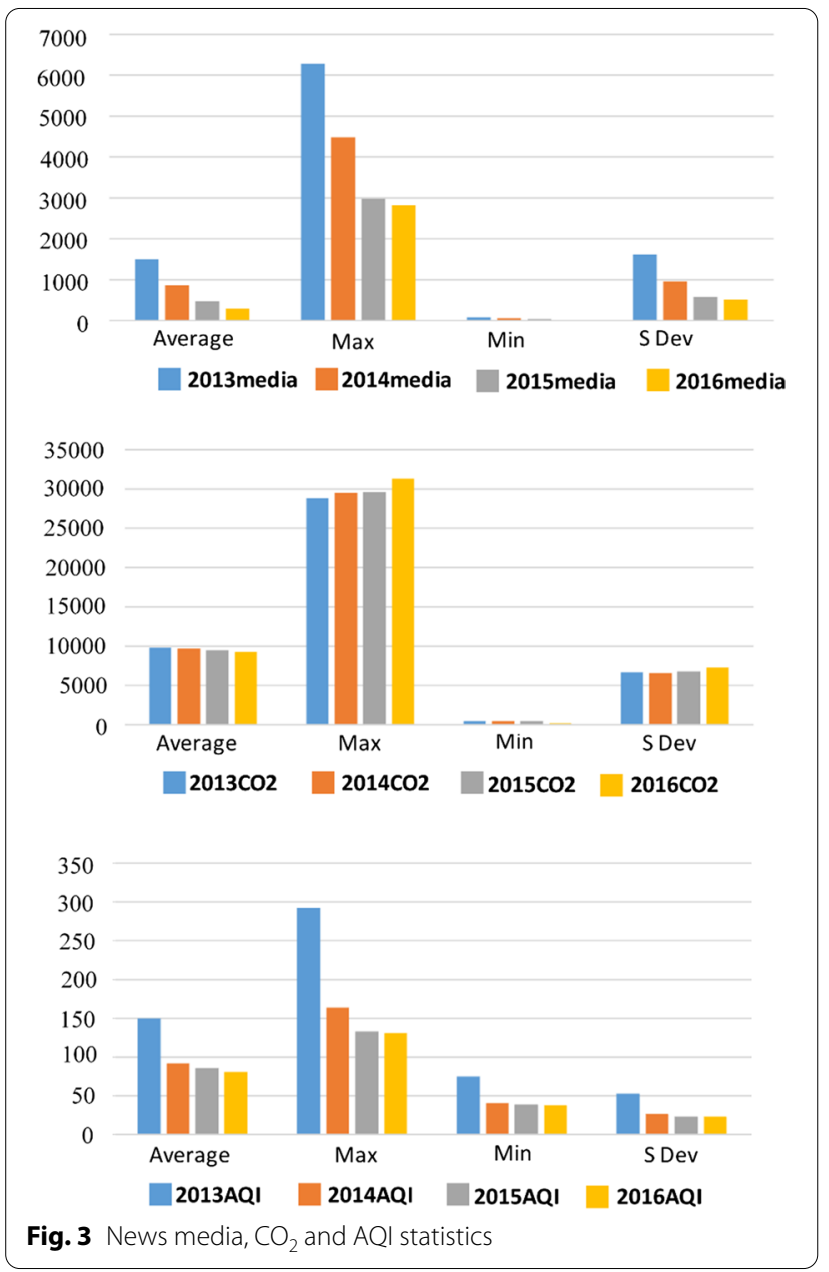

efficiencies in Changchun and Harbin increased from 2013 to 2014, but decreased in the last two years. The efficiencies in Chengdu and Xi'an both fell from 1 in 2013 to less than 0.8 in 2016.

\section{Input and output efficiency indicators}

Table 3 shows the media report efficiencies in the 31 cities from 2013 to 2016, from which it can be seen that a downward efficiency trend was more obvious than an upward trend. Chongqing, Guangzhou, Kunming, Nanning, and Shanghai had media efficiencies of 1, Xi'an had a media efficiency of 0.9544 in 2015, and 1 in all other years, Beijing's media efficiency was 1 from 2013 to 2015, but only 0.0888 in 2016, Hefei, Lanzhou, Nanchang, Nanjing, Shijiazhuang, Urumqi, Xining, and Yinchuan had lower media efficiencies, Lanzhou, Shijiazhuang, Xining, Yinchuan and Urumqi's media report efficiencies were below 0.4, and the lowest efficiency was in Nanning at below 0.3 .

The media report efficiency was only rising in Jinan from 0.1 in 2013 to 1 in 2016, and the efficiency in Lhasa was 1 in 2013 to 2016 but in the middle years was less than 0.5 . All other 23 cities had falling media report efficiencies, with the largest decline being in Wuhan from 1 in 2013 to 0.3 in 2016. Therefore, the media report efficiencies in most cities had little impact on environmental governance.

Table 4 shows the energy consumption efficiencies in the 31 Chinese cities from 2013 to 2016. Beijing, Chongqing, Guangzhou, Nanning, Shanghai had energy 
Table 2 Annual overall efficiencies in 31 Chinese cities from 2013 to 2016

\begin{tabular}{|c|c|c|c|c|c|}
\hline No. & City & 2013 & 2014 & 2015 & 2016 \\
\hline 1 & Beijing & 1.0000 & 1.0000 & 1.0000 & 0.6572 \\
\hline 2 & Changchun & 0.6605 & 0.7283 & 0.5380 & 0.5798 \\
\hline 3 & Changsha & 0.5716 & 0.4837 & 0.4817 & 0.5052 \\
\hline 4 & Chengdu & 1.0000 & 0.9353 & 0.7527 & 0.7289 \\
\hline 5 & Chongqing & 1.0000 & 1.0000 & 1.0000 & 1.0000 \\
\hline 6 & Fuzhou & 0.7017 & 0.5871 & 0.5372 & 0.5310 \\
\hline 7 & Guangzhou & 1.0000 & 1.0000 & 1.0000 & 1.0000 \\
\hline 8 & Guiyang & 0.5288 & 0.5546 & 0.5564 & 0.5386 \\
\hline 9 & Harbin & 0.7303 & 0.8016 & 0.5205 & 0.5229 \\
\hline 10 & Haikou & 0.6274 & 0.5166 & 0.4795 & 0.6234 \\
\hline 11 & Hangzhou & 0.5889 & 0.5369 & 0.5210 & 0.5609 \\
\hline 12 & Hefei & 0.4867 & 0.4744 & 0.4586 & 0.4657 \\
\hline 13 & Huhehot & 0.5686 & 0.5324 & 0.6147 & 0.5608 \\
\hline 14 & Jinan & 0.3959 & 0.3946 & 0.4252 & 1.0000 \\
\hline 15 & Kunming & 0.6139 & 0.6060 & 0.6949 & 0.7064 \\
\hline 16 & Lanzhou & 0.3362 & 0.3344 & 0.3000 & 0.3001 \\
\hline 17 & Lhasa & 0.6308 & 0.5204 & 0.4840 & 0.6040 \\
\hline 18 & Nanchang & 0.5019 & 0.4876 & 0.4456 & 0.4458 \\
\hline 19 & Nanjing & 0.3920 & 0.4478 & 0.4988 & 0.5019 \\
\hline 20 & Nanning & 1.0000 & 1.0000 & 1.0000 & 1.0000 \\
\hline 21 & Shanghai & 1.0000 & 1.0000 & 1.0000 & 1.0000 \\
\hline 22 & Shenyang & 0.6182 & 0.6326 & 0.5003 & 0.6422 \\
\hline 23 & Shijiazhuang & 0.3665 & 0.3588 & 0.3651 & 0.3482 \\
\hline 24 & Taiyuan & 0.3471 & 0.3561 & 0.3413 & 0.3092 \\
\hline 25 & Tianjin & 0.6600 & 0.5658 & 0.5154 & 0.5486 \\
\hline 26 & Wuhan & 0.6552 & 0.5799 & 0.5606 & 0.5324 \\
\hline 27 & Urumqi & 0.4294 & 0.4298 & 0.4406 & 0.4371 \\
\hline 28 & Xian & 1.0000 & 0.8713 & 0.8277 & 0.7607 \\
\hline 29 & Xining & 0.2768 & 0.2900 & 0.2703 & 0.3988 \\
\hline 30 & Yinchuan & 0.3511 & 0.3311 & 0.2934 & 0.2764 \\
\hline 31 & Zhengzhou & 0.6317 & 0.5207 & 0.5340 & 0.5959 \\
\hline
\end{tabular}

consumption efficiencies of 1 , Chengdu, Lhasa, Haikou, Hefei and Xi'an all attained 1 in three years, Changsha, Lanzhou, Shijiazhuang, Tianjin and Yinchuan had lower efficiencies, and the lowest energy consumption efficiency was in Taiyuan with all years below 0.3.

Changchun, Changsha, Fuzhou, Guiyang, Hangzhou, Hefei, Hohhot, Kunming, Nanjing, Shenyang, Taiyuan, Tianjin, Wuhan, and Xining had rising energy consumption efficiencies, and Harbin, Lanzhou, Nanchang, Urumqi, Yinchuan, and Zhengzhou had falling energy consumption efficiencies.

Table 5 indicates that the GDP efficiencies were high in most cities, with 17 of the 31 cities having efficiencies greater than 0.8. Beijing, Changchun, Guangzhou,
Table 3 Media report efficiencies

\begin{tabular}{|c|c|c|c|c|c|}
\hline No. & DUM & $\begin{array}{l}2013 \\
\text { Media }\end{array}$ & $\begin{array}{l}2014 \\
\text { Media }\end{array}$ & $\begin{array}{l}2015 \\
\text { Media }\end{array}$ & 2016 Media \\
\hline 1 & Beijing & 1.0000 & 1.0000 & 1.0000 & 0.0888 \\
\hline 2 & Changchun & 1.0000 & 1.0000 & 0.4530 & 0.5095 \\
\hline 3 & Changsha & 0.7947 & 0.2940 & 0.2613 & 0.3511 \\
\hline 4 & Chengdu & 1.0000 & 1.0000 & 0.6895 & 0.7018 \\
\hline 5 & Chongqing & 1.0000 & 1.0000 & 1.0000 & 1.0000 \\
\hline 6 & Fuzhou & 1.0000 & 0.5194 & 0.2958 & 0.2476 \\
\hline 7 & Guangzhou & 1.0000 & 1.0000 & 1.0000 & 1.0000 \\
\hline 8 & Guiyang & 1.0000 & 1.0000 & 0.7661 & 0.6939 \\
\hline 9 & Harbin & 1.0000 & 1.0000 & 0.3266 & 0.3145 \\
\hline 10 & Haikou & 1.0000 & 0.5106 & 0.3486 & 1.0000 \\
\hline 11 & Hangzhou & 0.7641 & 0.2972 & 0.1757 & 0.2636 \\
\hline 12 & Hefei & 0.5486 & 0.2558 & 0.1693 & 0.1610 \\
\hline 13 & Huhehaote & 1.0000 & 0.6771 & 0.8171 & 0.6576 \\
\hline 14 & Jinan & 0.1230 & 0.2002 & 0.2545 & 1.0000 \\
\hline 15 & Kunming & 1.0000 & 1.0000 & 1.0000 & 1.0000 \\
\hline 16 & Lanzhou & 0.3103 & 0.3244 & 0.2357 & 0.1733 \\
\hline 17 & Lhasa & 1.0000 & 0.4733 & 0.3449 & 1.0000 \\
\hline 18 & Nanchang & 0.4642 & 0.2935 & 0.1600 & 0.3062 \\
\hline 19 & Nanjing & 0.1958 & 0.2582 & 0.1836 & 0.1670 \\
\hline 20 & Nanning & 1.0000 & 1.0000 & 1.0000 & 1.0000 \\
\hline 21 & Shanghai & 1.0000 & 1.0000 & 1.0000 & 1.0000 \\
\hline 22 & Shenyang & 1.0000 & 1.0000 & 0.4420 & 0.9326 \\
\hline 23 & $\begin{array}{l}\text { Shiji- } \\
\text { azhuang }\end{array}$ & 0.3354 & 0.2719 & 0.2119 & 0.2302 \\
\hline 24 & Taiyuan & 0.6766 & 0.7599 & 0.6630 & 0.4026 \\
\hline 25 & Tianjin & 1.0000 & 0.7134 & 0.5127 & 0.5948 \\
\hline 26 & Wuhan & 1.0000 & 0.5060 & 0.3925 & 0.2920 \\
\hline 27 & Wulumuqi & 0.1846 & 0.2157 & 0.1367 & 0.3238 \\
\hline 28 & Xian & 1.0000 & 1.0000 & 0.9544 & 1.0000 \\
\hline 29 & Xining & 0.2904 & 0.3670 & 0.2216 & 0.2259 \\
\hline 30 & Yinchuan & 0.3333 & 0.2819 & 0.2000 & 0.1148 \\
\hline 31 & Zhengzhou & 0.4463 & 0.1225 & 0.0942 & 0.8728 \\
\hline
\end{tabular}

Chongqing, Nanning, and Shanghai all had GDP efficiencies of 1, Harbin and Zhengzhou had efficiencies of 1 in three years, and Nanjing, Tianjin, and Nanchang had efficiencies of 1 for two years. Fuzhou, Haikou, Hohhot, Lanzhou, Lhasa, Shijiazhuang, Taiyuan, Urumqi, Xining and Yinchuan, Lanzhou, Shijiazhuang and Xining had the lowest GDP efficiencies, with Fuzhou, Shijiazhuang, Taiyuan, Urumqi, Xining, and Yinchuan all having fluctuating efficiencies.

Changsha, Chengdu, Guiyang, Haikou, Hohhot, Wuhan, Xi'an, Kunming, and Hangzhou had falling GDP efficiencies, with Guiyang's falling from 0.8144 in 2013 to 0.6585 in 2016. Xi'an attained 1 in both 2013 and 2014, but in the following two years, the GDP efficiency fell to 0.8032 and 0.7667 . 
Table 4 Energy consumption efficiencies

\begin{tabular}{llllll}
\hline No. & DuM & $\mathbf{2 0 1 3}$ com & $\mathbf{2 0 1 4}$ com & $\mathbf{2 0 1 5}$ com & $\mathbf{2 0 1 6}$ com \\
\hline 1 & Beijing & 1.0000 & 1.0000 & 1.0000 & 1.0000 \\
2 & Changchun & 0.9000 & 1.0000 & 0.9629 & 0.9772 \\
3 & Changsha & 0.5937 & 0.7051 & 0.7119 & 0.6986 \\
4 & Chengdu & 1.0000 & 0.8444 & 1.0000 & 1.0000 \\
5 & Chongqing & 1.0000 & 1.0000 & 1.0000 & 1.0000 \\
6 & Fuzhou & 0.9534 & 0.9486 & 0.9783 & 0.9748 \\
7 & Guangzhou & 1.0000 & 1.0000 & 1.0000 & 1.0000 \\
8 & Guiyang & 0.5263 & 0.6662 & 0.8048 & 0.9157 \\
9 & Harbin & 0.9684 & 0.9994 & 0.8697 & 0.8388 \\
10 & Haikou & 1.0000 & 0.9326 & 1.0000 & 1.0000 \\
11 & Hangzhou & 0.6541 & 0.8137 & 0.8612 & 0.8664 \\
12 & Hefei & 0.7951 & 0.9984 & 1.0000 & 1.0000 \\
13 & Huhehaote & 0.4190 & 0.8416 & 0.8415 & 0.8026 \\
14 & Jinan & 0.6914 & 0.4810 & 0.5829 & 1.0000 \\
15 & Kunming & 0.5398 & 0.6160 & 0.8412 & 0.8496 \\
16 & Lanzhou & 0.5757 & 0.5676 & 0.4725 & 0.5080 \\
17 & Lhasa & 1.0000 & 0.9100 & 1.0000 & 1.0000 \\
18 & Nanchang & 0.9134 & 0.9957 & 0.9731 & 0.8402 \\
19 & Nanjing & 0.5853 & 0.5729 & 0.8323 & 0.8224 \\
20 & Nanning & 1.0000 & 1.0000 & 1.0000 & 1.0000 \\
21 & Shanghai & 1.0000 & 1.0000 & 1.0000 & 1.0000 \\
22 & Shenyang & 0.6613 & 0.6134 & 0.7766 & 0.9030 \\
23 & Shijiazhuang & 0.6944 & 0.7436 & 0.6312 & 0.6940 \\
24 & Taiyuan & 0.2522 & 0.2668 & 0.2607 & 0.3127 \\
25 & Tianjin & 0.6323 & 0.6352 & 0.6483 & 0.6683 \\
26 & Wuhan & 0.7425 & 0.8115 & 0.8543 & 0.8427 \\
27 & Wulumuqi & 0.8149 & 0.8573 & 0.9303 & 0.7825 \\
28 & Xian & 1.0000 & 0.8932 & 0.9999 & 1.0000 \\
29 & Xining & 0.4186 & 0.4207 & 0.4428 & 0.9703 \\
30 & Yinchuan & 0.5295 & 0.4735 & 0.3949 & 0.3796 \\
31 & Zhengzhou & 0.9966 & 0.9138 & 1.0000 & 0.5152 \\
\hline & & & & \\
\hline
\end{tabular}

Table 6 shows the $\mathrm{CO}_{2}$ emissions from 2013 to 2016, from which it can be seen that there were significant differences between the cities. Beijing, Chongqing, Guangzhou, Nanning and Shanghai had $\mathrm{CO}_{2}$ emissions efficiencies of 1 in all years, Chengdu, Haikou and Xi'an had $\mathrm{CO}_{2}$ emissions efficiencies of 1 in three years, and Changsha, Kunming, Lanzhou, Taiyuan, and Yinchuan had poor $\mathrm{CO}_{2}$ emissions efficiencies, with Taiyuan's performance being the worst at only 0.3127 .

Changsha, Fuzhou, Guiyang, Hangzhou, Hefei, Kunming, Lhasa, Tianjin and Xining Progress had rising $\mathrm{CO}_{2}$ emissions efficiencies with Hefei's rising to 1 in 2015 and 2016, Kunming's and Nanjing's rising in 2015 and 2016, and Xining having a $\mathrm{CO}_{2}$ emissions efficiency of less than 0.5 in the first three years, but 0.9704 in 2016. However, the $\mathrm{CO}_{2}$ emissions efficiencies in Harbin, Urumqi and Zhengzhou fell; Zhengzhou's
Table 5 GDP efficiencies

\begin{tabular}{llllll}
\hline No. & DMU & $\mathbf{2 0 1 3}$ GDP & $\mathbf{2 0 1 4}$ GDP & $\mathbf{2 0 1 5}$ GDP & $\mathbf{2 0 1 6}$ GDP \\
\hline 1 & Beijing & 1.0000 & 1.0000 & 1.0000 & 1.0000 \\
2 & Changchun & 1.0000 & 1.0000 & 1.0000 & 1.0000 \\
3 & Changsha & 1.0000 & 0.8790 & 0.8816 & 0.8892 \\
4 & Chengdu & 1.0000 & 1.0000 & 0.9082 & 0.8524 \\
5 & Chongqing & 1.0000 & 1.0000 & 1.0000 & 1.0000 \\
6 & Fuzhou & 0.7228 & 0.7159 & 0.7169 & 0.7226 \\
7 & Guangzhou & 1.0000 & 1.0000 & 1.0000 & 1.0000 \\
8 & Guiyang & 0.8144 & 0.7488 & 0.6772 & 0.6585 \\
9 & Harbin & 0.9223 & 1.0000 & 1.0000 & 1.0000 \\
10 & Haikou & 0.6923 & 0.6939 & 0.6755 & 0.6694 \\
11 & Hangzhou & 1.0000 & 0.8637 & 0.8686 & 0.8782 \\
12 & Hefei & 1.0000 & 0.8612 & 0.8665 & 0.8834 \\
13 & Huhehaote & 0.8440 & 0.8093 & 0.8022 & 0.7931 \\
14 & Jinan & 0.7322 & 1.0000 & 0.8009 & 1.0000 \\
15 & Kunming & 1.0000 & 0.8223 & 0.8243 & 0.8605 \\
16 & Lanzhou & 0.6286 & 0.6285 & 0.6348 & 0.6416 \\
17 & Lhasa & 0.7042 & 0.7168 & 0.6770 & 0.6695 \\
18 & Nanchang & 1.0000 & 0.9359 & 0.9413 & 1.0000 \\
19 & Nanjing & 1.0000 & 0.9834 & 1.0000 & 0.9973 \\
20 & Nanning & 1.0000 & 1.0000 & 1.0000 & 1.0000 \\
21 & Shanghai & 1.0000 & 1.0000 & 1.0000 & 1.0000 \\
22 & Shenyang & 0.8619 & 1.0000 & 0.7578 & 0.7071 \\
23 & Shijiazhuang & 0.6198 & 0.6158 & 0.6266 & 0.6221 \\
24 & Taiyuan & 0.6549 & 0.6498 & 0.6554 & 0.6629 \\
25 & Tianjin & 1.0000 & 1.0000 & 0.9715 & 0.9698 \\
26 & Wuhan & 0.8735 & 0.8238 & 0.8237 & 0.8281 \\
27 & Urumqi & 0.7035 & 0.6951 & 0.6967 & 0.6891 \\
28 & Xian & 1.0000 & 1.0000 & 0.8032 & 0.7667 \\
29 & Xining & 0.6097 & 0.6128 & 0.6122 & 0.6194 \\
30 & Yinchuan & 0.6740 & 0.6738 & 0.6735 & 0.6808 \\
31 & Zhengzhou & 0.9516 & 1.0000 & 1.0000 & 1.0000 \\
\hline & & & & &
\end{tabular}

efficiency was greater than 0.9 in the first three years but only 0.5149 in 2016 .

The $\mathrm{CO}_{2}$ emissions efficiency improvements in most cities were significant, possibly because of the media reports and regulatory governance measures.

Table 7 shows the AQI efficiencies in the 31 Chinese cities from 2013 to 2016, from which it can be seen that the overall efficiencies in most cities were below 0.5.

The AQI efficiencies in Chongqing, Guangzhou, Nanning and Shanghai were 1 in all years and Beijing's was 0.9545 in 2015, and 1 in all others years. However, few other cities had efficiencies greater than 0.8. Chengdu's AQI efficiency was 1 in 2013 and 2014, but its 2015 and 2016 efficiencies were 0.5392 and 0.5384 , and the AQI efficiencies in Changchun, Changsha, Guiyang, Haikou, Hefei, Hohhot, Lanzhou, Lhasa, Nanchang, Taiyuan, Urumqi, Xining and Yinchuan were all less than 0.4. 
Table $6 \mathrm{CO}_{2}$ emissions efficiencies

\begin{tabular}{llllll}
\hline No. & DMU & $\mathbf{2 0 1 3} \mathbf{C O}_{\mathbf{2}}$ & $\mathbf{2 0 1 4} \mathbf{C O}_{\mathbf{2}}$ & $\mathbf{2 0 1 5} \mathbf{C O}_{\mathbf{2}}$ & $\mathbf{2 0 1 6} \mathbf{C O}_{\mathbf{2}}$ \\
\hline 1 & Beijing & 1.0000 & 1.0000 & 1.0000 & 0.9999 \\
2 & Changchun & 0.9501 & 0.9773 & 0.9631 & 0.9771 \\
3 & Changsha & 0.5871 & 0.7055 & 0.7119 & 0.6986 \\
4 & Chengdu & 1.0000 & 0.9587 & 1.0000 & 1.0000 \\
5 & Chongqing & 1.0000 & 1.0000 & 1.0000 & 1.0000 \\
6 & Fuzhou & 0.9019 & 1.0000 & 0.9783 & 0.9747 \\
7 & Guangzhou & 1.0000 & 1.0000 & 1.0000 & 1.0000 \\
8 & Guiyang & 0.5823 & 0.6059 & 1.0000 & 0.9156 \\
9 & Harbin & 1.0000 & 1.0000 & 0.8694 & 0.8386 \\
10 & Haikou & 0.9311 & 1.0000 & 1.0000 & 1.0000 \\
11 & Hangzhou & 0.6579 & 0.7990 & 0.8613 & 0.8663 \\
12 & Hefei & 0.7952 & 0.9847 & 0.9999 & 1.0000 \\
13 & Huhehaote & 0.8094 & 0.4363 & 0.8417 & 0.8027 \\
14 & Jinan & 0.6888 & 0.4811 & 0.5828 & 1.0000 \\
15 & Kunming & 0.5492 & 0.6093 & 0.8413 & 0.8496 \\
16 & Lanzhou & 0.5676 & 0.5757 & 0.4725 & 0.5080 \\
17 & Lhasa & 0.9078 & 1.0000 & 0.9975 & 0.9999 \\
18 & Nanchang & 0.9044 & 1.0000 & 0.9732 & 0.8400 \\
19 & Nanjing & 0.5543 & 0.6039 & 0.8323 & 0.8223 \\
20 & Nanning & 1.0000 & 1.0000 & 1.0000 & 1.0000 \\
21 & Shanghai & 1.0000 & 1.0000 & 1.0000 & 1.0000 \\
22 & Shenyang & 0.6833 & 0.5926 & 0.7766 & 0.9030 \\
23 & Shijiazhuang & 0.7436 & 0.6944 & 1.0000 & 0.6940 \\
24 & Taiyuan & 0.2691 & 0.2497 & 0.2607 & 0.3127 \\
25 & Tianjin & 0.6306 & 0.6370 & 0.6483 & 0.6682 \\
26 & Wuhan & 0.7127 & 0.8393 & 0.8543 & 0.8426 \\
27 & Wulumuqi & 0.8574 & 0.8148 & 0.9301 & 0.7824 \\
28 & Xian & 1.0000 & 0.9482 & 1.0000 & 0.9998 \\
29 & Xining & 0.4210 & 0.4182 & 0.4427 & 0.9704 \\
30 & Yinchuan & 0.4735 & 0.5294 & 0.3949 & 0.3796 \\
31 & Zhengzhou & 1.0000 & 0.9102 & 0.9999 & 0.5149 \\
\hline & & & & &
\end{tabular}

Therefore, there was a significant need for AQI efficiency improvements in most cities.

Changchun, Changsha, Harbin, Hangzhou, Hefei, Jinan, Nanchang, Nanjing and Zhengzhou had rising AQI efficiencies, with Jinan's rising from 0.3054 in 2013 to 1.0000 in 2016. However, Chengdu, Fuzhou, Hohhot, Lanzhou, Lhasa, Taiyuan, Tianjin, Xi'an, Xining, Yinchuan all had falling AQI efficiencies. Most cities were found to have poor AQI efficiencies, and there was insufficient evidence to determine the effects of the media reports.

\section{Media reports, $\mathrm{CO}_{2}$ and $\mathrm{AQI}$ analyses}

Table 8 shows the media report, $\mathrm{CO}_{2}$ emissions, and AQI efficiencies in the 31 Chinese cities from 2013 to 2016. When the news media reports were considered as an input indicator, the AQI efficiencies were significantly lower than the $\mathrm{CO}_{2}$ emissions efficiencies. Shanghai,
Table 7 AQI efficiencies

\begin{tabular}{llllll}
\hline No. & DMU & $\mathbf{2 0 1 3}$ AQI & $\mathbf{2 0 1 4}$ AQI & $\mathbf{2 0 1 5}$ AQI & $\mathbf{2 0 1 6}$ AQI \\
\hline 1 & Beijing & 1.0000 & 1.0000 & 1.0000 & 0.9545 \\
2 & Changchun & 0.2447 & 0.3204 & 0.2647 & 0.3300 \\
3 & Changsha & 0.2345 & 0.3802 & 0.3750 & 0.3910 \\
4 & Chengdu & 1.0000 & 1.0000 & 0.5392 & 0.5384 \\
5 & Chongqing & 1.0000 & 1.0000 & 1.0000 & 1.0000 \\
6 & Fuzhou & 0.6379 & 0.6191 & 0.5834 & 0.5540 \\
7 & Guangzhou & 1.0000 & 1.0000 & 1.0000 & 1.0000 \\
8 & Guiyang & 0.1914 & 0.2634 & 0.3708 & 0.3168 \\
9 & Harbin & 0.4610 & 0.5897 & 0.4827 & 0.5877 \\
10 & Haikou & 0.2787 & 0.3596 & 0.3042 & 0.3070 \\
11 & Hangzhou & 0.2570 & 0.5264 & 0.4464 & 0.4976 \\
12 & Hefei & 0.1094 & 0.2396 & 0.2356 & 0.2441 \\
13 & Huhehaote & 0.2182 & 0.1823 & 0.1603 & 0.1631 \\
14 & Jinan & 0.3054 & 0.3339 & 0.4272 & 1.0000 \\
15 & Kunming & 0.4146 & 0.4247 & 0.3997 & 0.3721 \\
16 & Lanzhou & 0.2828 & 0.2132 & 0.1877 & 0.1546 \\
17 & Lhasa & 0.0831 & 0.0732 & 0.0701 & 0.0595 \\
18 & Nanchang & 0.1615 & 0.2230 & 0.2040 & 0.2392 \\
19 & Nanjing & 0.2781 & 0.6482 & 0.3665 & 0.3919 \\
20 & Nanning & 1.0000 & 1.0000 & 1.0000 & 1.0000 \\
21 & Shanghai & 1.0000 & 1.0000 & 1.0000 & 1.0000 \\
22 & Shenyang & 0.3846 & 0.4561 & 0.3357 & 0.3888 \\
23 & Shijiazhuang & 0.3057 & 0.3464 & 0.4253 & 0.3270 \\
24 & Taiyuan & 0.2875 & 0.2278 & 0.2110 & 0.1739 \\
25 & Tianjin & 0.6446 & 0.5446 & 0.5353 & 0.5187 \\
26 & Wuhan & 0.2862 & 0.4879 & 0.4537 & 0.4099 \\
27 & Urumqi & 0.2149 & 0.1629 & 0.1496 & 0.2212 \\
28 & Xian & 1.0000 & 0.7312 & 0.7551 & 0.4939 \\
29 & Xining & 0.1838 & 0.1319 & 0.1277 & 0.1167 \\
30 & Yinchuan & 0.1582 & 0.1375 & 0.1090 & 0.0963 \\
31 & Zhengzhou & 0.3712 & 0.5058 & 0.3957 & 0.8236 \\
\hline & & & & & \\
\hline
\end{tabular}

Nanning, Chongqing and Guangzhou had AQI efficiencies of 1, Chengdu had an AQI efficiency of 1 in 2013 and 2014, but suffered a significant decline in 2015 and 2016, Jinan's AQI efficiency rose to 1 in 2016, and the other 24 cities had AQI efficiencies below 0.5.

Therefore, the media news reports efficiencies in the cities with low AQI efficiencies required significant improvement. Hangzhou, Hefei, Nanchang, Nanjing, Shijiazhuang, Wuhan, Urumqi, Xining and Zhengzhou had $\mathrm{CO}_{2}$ emissions efficiencies higher than 0.8 , but the $\mathrm{CO}_{2}$ emissions efficiencies in Changsha, Lanzhou, Taiyuan, Tianjin and Yinchuan were less than 0.8.

The media report efficiency fluctuations were found to be consistent with the AQI efficiency fluctuations, and the media reports in most cities had a more positive impact on $\mathrm{CO}_{2}$ emissions efficiencies than AQI efficiencies. 


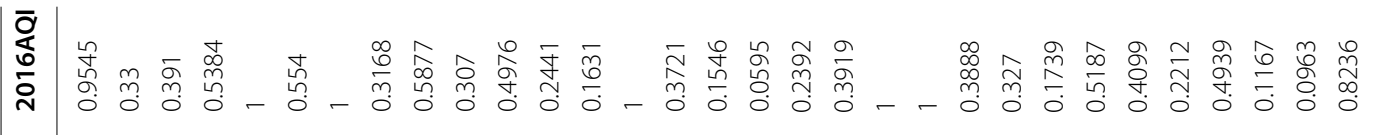

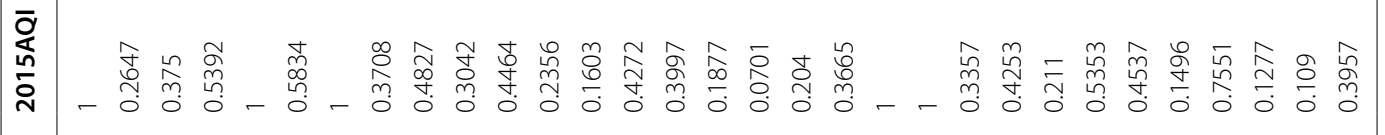

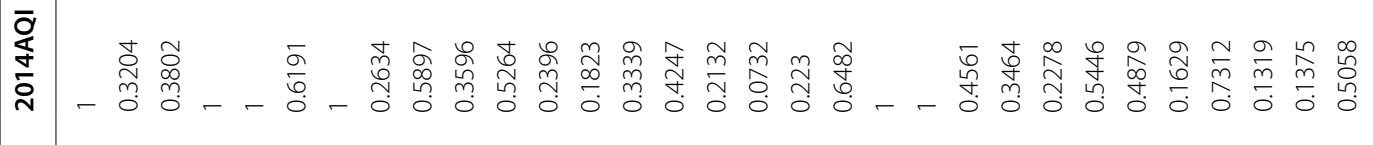

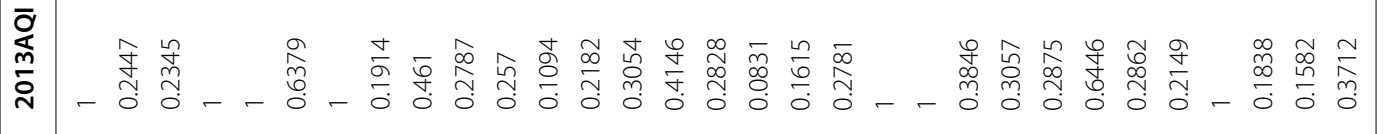

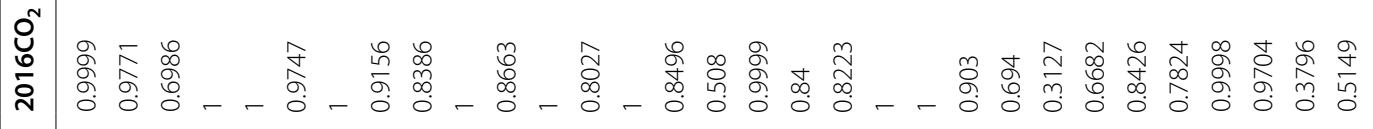

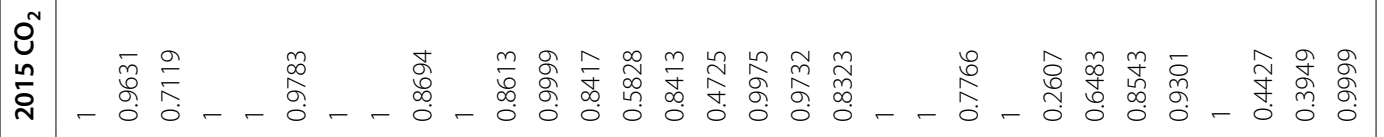

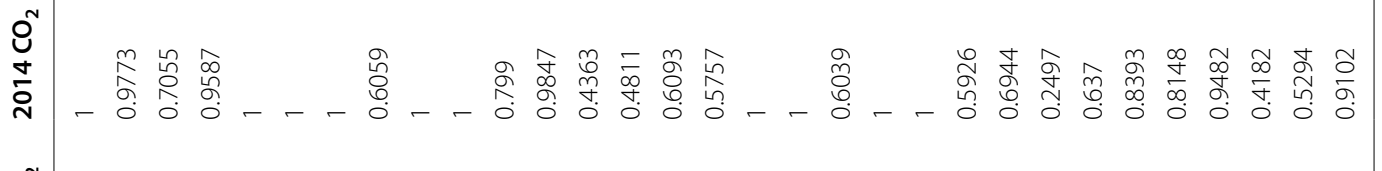

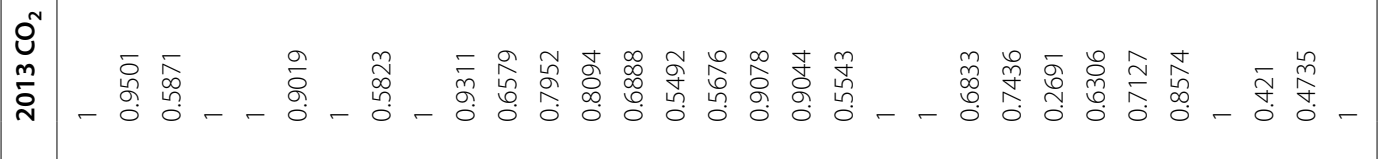

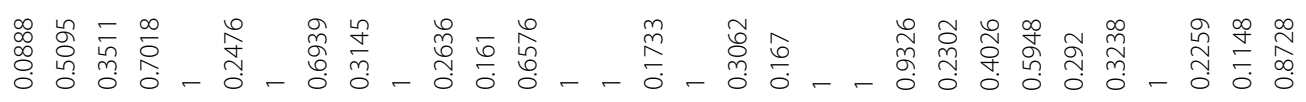

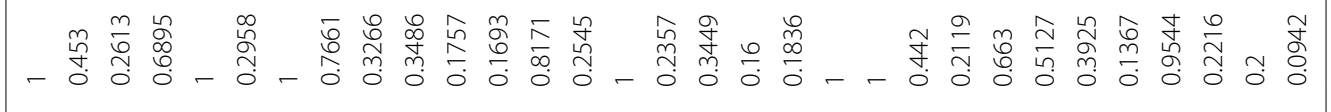
- - 苟 


\section{Index efficiencies in each city and key areas for improvement}

The input and output indicator efficiencies in each city from 2013 to 2016 were further examined to identify the needed improvements and are summarized in Table 9.

The differences in the regional urban characteristics and resource endowments have led to differences in industrial structures and production methods in each city, and the impact of media reports on $\mathrm{CO}_{2}$ emissions $\mathrm{s}$ and the AQI also varied widely, all of which meant that there were significant differences in the improvement needs. For example, in 2016, Beijing needed greater improvements in media reports and air quality efficiencies than in other years. Urumqi and Zhengzhou also need to place priority on improving media report and AQI efficiencies, Changsha and Taiyuan need AQI and $\mathrm{CO}_{2}$ emissions efficiency improvements, and Guiyang, Hohhot, Lanzhou, Lhasa, Shenyang, Xi'an and Xining all need to prioritize AQI and GDP efficiencies.

\section{Conclusions}

This study used a modified undesirable dynamic DEA to study the energy consumption, environmental, and media report efficiencies in 31 Chinese cities, the conclusions from which were as follows.

First, Chongqing, Guangzhou, Nanjing, and Shanghai had overall efficiencies of 1 , and the worst overall efficiencies were in Lanzhou, Shijiazhuang, Taiyuan, Xining and Yinchuan. The efficiencies in 12 cities declined, and the overall efficiencies in 5 cities fluctuated.

Second, Chongqing, Guangzhou, Kunming, Nanning and Shanghai had media report efficiencies of 1, Hefei, Nanchang, Nanjing, Urumqi, Xining, Yinchuan had the worst media report efficiencies, the efficiencies in Jinan and Urumqi increased, and the other 23 cities had reduced media report efficiencies.

Third, Beijing, Chongqing, Guangzhou, Nanning, and Shanghai had energy consumption efficiencies of 1 , the energy consumption efficiencies in Taiyuan. Harbin, Lanzhou, Nanchang, Urumqi, Yunnan and Zhengzhou declined, and the energy consumption efficiencies in Changchun, Changsha, Fuzhou, Guiyang, Hangzhou, Hefei, Hohhot, Kunming, Nanjing, Shenyang, Taiyuan, Tianjin, Wuhan, and Xining increased.

Fourth, Beijing, Changchun, Guangzhou, Chongqing, Nanning, and Shanghai had GDP efficiencies of 1, Fuzhou, Shijiazhuang, Taiyuan, Urumqi, Xining, and Yinchuan's had increasing GDP efficiencies, and Changsha, Chengdu, Guiyang, Haikou, Hohhot, Wuhan, Xi'an, Kunming, and Hangzhou had decreasing GDP efficiencies.

Fifth, Beijing, Chongqing, Guangzhou, Nanning and Shanghai had $\mathrm{CO}_{2}$ emissions efficiencies of 1 , Changsha,
Fuzhou, Guiyang, Hangzhou, Hefei, Kunming, Lhasa, Tianjin and Xining had increasing $\mathrm{CO}_{2}$ emissions efficiencies, Harbin, Urumqi and Zhengzhou's had falling $\mathrm{CO}_{2}$ emissions efficiencies, and Taiyuan had the worst $\mathrm{CO}_{2}$ emissions efficiency.

Sixth, the overall AQI efficiencies in the 31 cities were low. While 13 cities had AQI efficiencies of 1, 10 cities had significant declines. No evidence was found to indicate that media reports had any impact on air pollution efficiency improvements.

\section{Policy implication}

The governance focus, therefore, should be on improving the $\mathrm{CO}_{2}$ emissions and $\mathrm{AQI}$ efficiencies to prepare for the challenges of dealing with climate change and coordinating economic growth and environmental protection. Based on the above conclusions, the following management recommendations are given.

First, energy and industrial structural adjustments can improve the AQI efficiency. Of the 31 cities, at least 21 cities need AQI efficiency improvements, most of which have middle economic and social development levels, such as Changchun, Changsha, Fuzhou, Guiyang, Harbin, Hefei, Kunming, Lhasa, Nanchang, Nanjing, Shenyang, Shijiazhuang, Taiyuan, Wuhan, Urumqi, Xining, and Yinchuan. The economic growth and social development in these cities depend on traditional fossil fuel energy and traditional manufacturing and secondary industries that consume fossil energy. By adjusting their energy and industrial structures, the $\mathrm{AQI}$ and $\mathrm{CO}_{2}$ efficiencies could be improved.

Second, media report efficiency improvements need government support and encouragement. The media report content and effectiveness should be fully investigated and greater encouragement and support given to journalists and media outlets to encourage them to learn about environmental air protection and air pollution emissions and ensure media news report quality. At the same time, media workers need to keep their mission in mind and correctly guide the behavior of residents and businesses through active and accurate news reports. It is also necessary to actively play a supervisory role through media news reports to expose companies that violate regulations. As environmental awareness enhances the health of civilians and promotes economic growth, the news media needs to promote environmental protection and increase its environmental pollution coverage.

Third, news reports need to be timely when reporting on environmental issues, which also requires that government departments provide timely information to the public and the media. The news media could alert the public to environmental issues, which could assist in reducing the hazards or damage caused. 
Table 9 Improvements in each city

\begin{tabular}{|c|c|c|}
\hline No. & DMU & Improvement \\
\hline 1 & Beijing & The 2016 media and AQI efficiencies need improvements \\
\hline 2 & Changchun & $\begin{array}{l}\text { Measures need to be taken for labor input efficiency, the news media efficiency also dropped significantly in the last two years, and } \\
\text { there is a need to strengthen the AQI efficiency }\end{array}$ \\
\hline 3 & Changsha & $\begin{array}{l}\text { The media report, energy consumption, } \mathrm{CO}_{2} \text { emissions and } \mathrm{AQ} \text { l efficiencies need significant improvements, with the most serious } \\
\text { governance attention needed on } \mathrm{AQI} \text { and then } \mathrm{CO}_{2} \text { emissions }\end{array}$ \\
\hline 4 & Chengdu & Both media report and AQI efficiencies need priority governance and the GDP efficiency also needs attention \\
\hline 5 & Chongqing & There was no need for improvements as all input and output indicators were efficient \\
\hline 6 & Fuzhou & $\begin{array}{l}\text { Media efficiency dropped significantly, and there are also improvements needed in GDP efficiency. While the AQI efficiency had } \\
\text { significant improvements, greater efforts are needed }\end{array}$ \\
\hline 7 & Guangzhou & The improvement space for each indicator is 0 \\
\hline 8 & Guiyang & $\begin{array}{l}\text { Media report efficiency fell, and energy efficiency rose. However, priority governance and focus are needed in GDP and AQI effi- } \\
\text { ciencies, and } \mathrm{CO}_{2} \text { emissions efficiency also needs attention }\end{array}$ \\
\hline 9 & Harbin & $\begin{array}{l}\text { Labor input efficiency is rising, but further governance is needed. The news media efficiency declined significantly in the last two } \\
\text { years, even though the efficiency was fluctuating, significant AQI improvements are also needed, }\end{array}$ \\
\hline 10 & Haikou & $\begin{array}{l}\text { Media report efficiency had significant fluctuations, falling to a minimum in 2015, and then rising to 1, and while the GDP efficiency } \\
\text { improved, more attention is needed }\end{array}$ \\
\hline 11 & Hangzhou & $\begin{array}{l}\text { As the media report efficiency dropped significantly, the room for improvement remained large. The } \mathrm{AQI} \text { and } \mathrm{CO}_{2} \text { emissions effi- } \\
\text { ciencies need priority co-governance }\end{array}$ \\
\hline 12 & Hefei & $\begin{array}{l}\text { Media report efficiency declined, and labor input efficiency need improvements. Although the AQI efficiency slightly improved, the } \\
\text { highest was only 0.24; therefore, there is still a great need for proper governance }\end{array}$ \\
\hline 13 & Huhehaote & $\begin{array}{l}\text { Priority needs to be given to vigorously managing AQI efficiency as the efficiency in } 2016 \text { was only 0.16. The media report effi- } \\
\text { ciency fluctuated but still needs to be addressed and governed }\end{array}$ \\
\hline 14 & Jinan & While the media report efficiency declined, and the AQI efficiency rose, both still need strong efficiency governance \\
\hline 15 & Kunming & $\begin{array}{l}\text { The media report efficiency continued to decline, and improvements should be prioritized, the energy consumption efficiency } \\
\text { needs focused governance, the AQl efficiency score was slightly better than the media report efficiency and should also be given } \\
\text { priority }\end{array}$ \\
\hline 16 & Lanzhou & $\begin{array}{l}\text { All indicators need improvements; priority governance should be given to the AQI and media report efficiencies, and there is also a } \\
\text { need for energy consumption, } \mathrm{CO}_{2} \text { emissions, } \mathrm{AQI} \text { and GDP efficiency governance improvements }\end{array}$ \\
\hline 17 & Lhasa & $\begin{array}{l}\text { Media efficiency fluctuated and was the best in 2016; however, further improvements are needed. AQI and GDP efficiencies also } \\
\text { need close governance attention }\end{array}$ \\
\hline 18 & Nanchang & $\begin{array}{l}\text { While there is less media report efficiency volatility, more improvements are needed. Further attention is needed to strengthen } \\
\text { labor input efficiency governance, and while the AQI efficiency increased slightly, significant improvements are still needed }\end{array}$ \\
\hline 19 & Nanjing & $\begin{array}{l}\text { Media report efficiency declined significantly, and AQI efficiency fluctuated; therefore, governance in both areas needs to be } \\
\text { strengthened }\end{array}$ \\
\hline 20 & Nanning & There was no need for improvements as all input and output indicators were efficient \\
\hline 21 & Shanghai & There was no need for improvements as all input and output indicators were efficient \\
\hline 22 & Shenyang & $\begin{array}{l}\text { The AQI efficiency is declining and priority governance is needed and while the } \mathrm{CO}_{2} \text { emissions and energy consumption efficien- } \\
\text { cies continued to rise, effective governance needs to be maintained }\end{array}$ \\
\hline 23 & Shijiazhuang & Media, energy consumption, and AQI efficiencies need continued governance \\
\hline 24 & Taiyuan & $\begin{array}{l}\text { GDP efficiency and especially energy consumption efficiency need priority attention, but some improvements are also needed in } \\
\text { media reporting. Overall, the governance of } \mathrm{AQI} \text {, and } \mathrm{CO}_{2} \text { emissions efficiencies should be strengthened }\end{array}$ \\
\hline 25 & Tianjin & $\begin{array}{l}\text { Improvements are needed in the media, energy consumption, } \mathrm{CO}_{2} \text { emissions, and } \mathrm{AQI} \text { efficiencies. Therefore, better overall govern- } \\
\text { ance is needed }\end{array}$ \\
\hline 26 & Wuhan & It is necessary to strengthen governance on the AQI and media report efficiencies \\
\hline 27 & Urumqi & $\begin{array}{l}\text { The media report and AQI efficiencies need priority governance, and the GDP and energy consumption efficiencies also need } \\
\text { attention }\end{array}$ \\
\hline 28 & Xian & $\begin{array}{l}\text { The GDP efficiency declined in the last two years and the AQI efficiency also fell; therefore, governance needs to be strengthened } \\
\text { in these two areas }\end{array}$ \\
\hline 29 & Xining & $\begin{array}{l}\text { AQI efficiency improvement needs priority governance, followed by GDP and media report efficiency, both of which declined. } \\
\text { While energy consumption efficiency increased significantly in the last year, attention is still needed }\end{array}$ \\
\hline 30 & Yinchuan & $\begin{array}{l}\text { Priority management is needed for } \mathrm{AQI} \text { efficiency, and media report efficiency also needs to be significantly improved. Further, as } \\
\mathrm{CO}_{2} \text { emissions and energy consumption efficiencies continued to decline, greater governance is needed }\end{array}$ \\
\hline 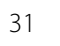 & Zhengzhou & While media report efficiency rose significantly in 2016, continued attention is needed, and AQI efficiency also needs improvement \\
\hline
\end{tabular}


Fourth, cities needs to increase their green areas, forest coverage, and carbon sink capacities, and adjust their energy structures by developing new energy technologies to replace traditional fossil fuel based energy, all of which would improve $\mathrm{CO}_{2}$ emissions efficiency. Although the $\mathrm{CO}_{2}$ emissions efficiencies were found to be slightly better than the AQI index efficiencies, $\mathrm{CO}_{2}$ emissions needs better governance in Lanzhou, Shijiazhuang, Taiyuan and Yinchuan as the dependence in these cities on traditional fossil energy has affected their $\mathrm{CO}_{2}$ emissions efficiencies. Through measures such as greening and economic, industrial, and energy structural challenges, $\mathrm{CO}_{2}$ emissions can be effectively reduced.

Fifth, media reports can have positive impact on carbon-emissions-friendly lifestyles and consumption. Residents cannot understand the climate change challenges, air pollution hazards, or prevention and control technologies if they are given insufficient awareness of the environmental impact of their individual choices. Therefore, accurate media reports are needed to encourage positive environmentally friendly behavioral change and government needs to encourage the media to strengthen their attention on the impact of climate change to better guide behavioral and lifestyle changes.

Sixth, the government needs to adopt environmentally focused market and fiscal policies, such as a carbon trading market, to encourage companies to choose environmentally friendly behaviors, implement positive behaviors, and fulfill their environmental and social responsibilities. Even though these cities have different industrial and energy structures, they need to develop and utilize new energy in accordance with local conditions to replace traditional fossil fuels. A carbon trading market could therefore assist in balancing economic development and environmental protection. Finally, the government needs to coordinate $\mathrm{CO}_{2}$ and other air pollutants with all stakeholders such as news media, residents, and enterprises to integrate resources and reduce costs. The media, residents, enterprises, scientific research institutions, schools, and non-government organizations need to work in harmony to reduce $\mathrm{CO}_{2}$ and other air pollutant emissions.

\section{Limitation and further research directions}

This research was focused on achieving atmospheric environmental efficiency in 31 Chinese cities to achieve effective $\mathrm{CO}_{2}$ and air pollutant emissions reductions, and therefore has strong practical significance and value. Due to time constraints and insufficient access to information, this study only used data from 2013 to 2016; therefore, the data needs to be updated in future research. In addition to time series data, new research could also divide the news media data to more fully examine the changes over time.

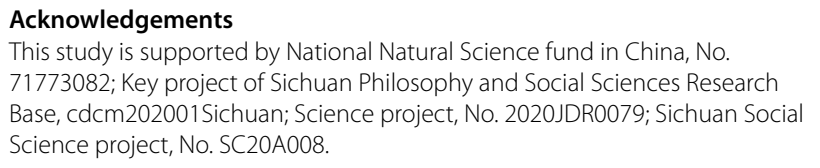

\section{Authors' contributions}

Conceptualization, $Y L$ and $Y C$; methodology, $Y L$ and $H C$; software, $Y C$ and $H C$; validation, YL, HC and TYL; formal analysis, YL and HC; investigation, HC, T-YL, $\mathrm{HC}$ and $\mathrm{YC}$; project administration, $\mathrm{YC}$ and $\mathrm{HC}$; funding acquisition, $\mathrm{YL}$. All authors read and approved the final manuscript.

\section{Availability of data and materials}

Not applicable.

\section{Declarations}

Ethics approval and consent to participate

This manuscript is a commentary article which has no human data collection.

Consent for publication

Not applicable.

Consent to participate

Not applicable.

\section{Competing interests}

The authors declare that they have no competing interests.

\section{Author details}

${ }^{1}$ Business School, Sichuan University, Wangjiang Road No. 29, Chengdu 610064, People's Republic of China. ${ }^{2}$ Department of Business Administration, National Cheng Kung University, No. 1, University Road, Tainan City 701, Taiwan, ROC. ${ }^{3}$ Department of Economics, Soochow University, 56, Kueiyang St., Sec. 1, Taipei 100, Taiwan, ROC. ${ }^{4}$ Sichuan University, Wangjiang Road No. 29, Chengdu 610064, People's Republic of China.

Received: 1 February 2020 Accepted: 28 July 2021

Published online: 16 August 2021

\section{References}

1. Abbas M, Zavadskasb EK, Streimikienec D, Jusoha A, Khoshnoudia M. A comprehensive review of data envelopment analysis (DEA) approach in energy efficiency. Renew Sustain Energy Rev. 2017;70:1298-322.

2. Bampatsou C, Papadopoulos S, Zervas E. Technical efficiency of economic systems of EU-15 countries based on energy consumption. Energy Policy. 2013;55:426-34.

3. Chen YM. Exploring the attitudinal variations in the Chinese Englishlanguage press on the 2013 air pollution incident. Discourse Commun. 2014;8(4):331-49.

4. Choi Y, Zhang N, Zhou P. Efficiency and abatement costs of energyrelated $\mathrm{CO}_{2}$ emissions in China: a slacks-based efficiency measure. Appl Energy. 2012;98:198-208.

5. Du K, Xie C, Ouyang X. A comparison of carbon dioxide $\left(\mathrm{CO}_{2}\right)$ emission trends among provinces in China. Renew Sustain Energy Rev. 2017;73:19-25.

6. Färe R, Grosskopf S, Norris M, Zhang Z. Productivity growth, technical progress, and efficiency change in industrialized countries. Am Econ Rev. 1994;84(1):66-83.

7. Feng C, Zhang, H, Huang, Jian-Bai. The approach to realizing the potential of emissions reduction in China: an implication from data envelopment analysis. Renew Sustain Energy Rev. 2017;71:859-872.

8. Foxwell-Norton K, Konkes C. The Great Barrier Reef: news media, policy and the politics of protection. Int Commun Gaz. 2019;81(3):211-34. 
9. Hu J-L, Wang S-C. Total-factor energy efficiency of regions in China. Energy Policy. 2006;34:3206-17.

10. Hu J-L, Chang M-C, Tsay H-W. The congestion total-factor energy efficiency of regions in Taiwan. Energy Policy. 2017;110:710-8.

11. Hswen Y, Qin Q, Brownstein JS, Hawkins JB. Feasibility of using social media to monitor outdoor air pollution in London, England. Prev Med. 2019;121:86-93.

12. Ikram M, Yan ZJ. Statistical analysis of the impact of AQI on respiratory disease in Beijing: application case 2009. Energy Procedia. 2017;107:340-4.

13. Jebali E, Essid $H$, Khraief N. The analysis of energy efficiency of the Mediterranean countries: a two-stage double bootstrap DEA approach. Energy. 2017;134:991-1000

14. Kay S, Zhao B, Sui D. Can social media clear the air? A case study of the air pollution problem in Chinese cities. Prof Geogr. 2015;67(3):351-63.

15. Kloop $\mathrm{G}$. The analysis of the efficiency of production system with multiple inputs and outputs. University of Illinois at Chicago. Industrial and Systems Engineering College. 1985.

16. Li Yi, Sun L, Feng T, Zhu C. How to reduce energy intensity in China: a regional comparison perspective. Energy Policy. 2013;61:513-22.

17. Lin $\mathrm{B}, \mathrm{Du} \mathrm{K}$. Energy and $\mathrm{CO}_{2}$ emissions performance in China's regional economies: do market-oriented reforms matter? Energy Policy. 2015;78:113-24.

18. Li Ke, Lin B. An application of a double bootstrap to investigate the effects of technological progress on total-factor energy consumption performance in China. Energy. 2017;128(1):575-85.

19. $\mathrm{Li}$ Y, Chiu YH, Lu LC. Energy, $\mathrm{CO}_{2}, \mathrm{AQI}$ and economic performance in 31 cities in China: a slacks-based dynamic data envelopment analysis. Carbon Manag. 2019;10(3):269-86.

20. Li Y, Chiu Y-h, Liang Chun Lu, Chiu C-J. Energy efficiency and air emission: an empirical study on 31 cities in China. Energy Eff. 2018;122:194-202.

21. Lowe P, Morrison D. Bad news or good news: Environmental politics and the mass media. Sociol Rev. 1984;32(1):75-90.

22. Malmquist S. Index numbers and indifference surfaces. Trabajos De Estadistica. 1953;4(2):209-42.

23. Mason M. The new accountability: environmental responsibility across borders. Routledge; 2012

24. Mayer B. Relax and take a deep breath': print media coverage of asthma and air pollution in the United States. Soc Sci Med. 2012;75(6):892-900.

25. McCreery AC. Media attention, political processes, and air pollution in the United States: a time-series analysis (1959-1998). Organ Environ. 2010;23(3):255-70.

26. Meng F, Su B, Thomson E, Zhou D, Zhou P. Measuring China's regional energy and carbon emission efficiency with DEA models: a survey. Appl Energy. 2016:183(1):1-21.
27. Mehmeti A, McPhail S, Ulgiati S. Fuel cell eco-efficiency calculator (FCEC): a simulation tool for the environmental and economic performance of high-temperature fuel cells. Energy. 2018;159:1195-205.

28. Niklas H, Sverker C, Johan M. Explaining ups and downs in the public's environmental concern in Sweden: the effects of ecological modernization, the economy, and the media. Organ Environ. 2011;24(4):388-403.

29. Qin Q, Li X, Li Li, Zhen W, Wei Y-M. Air emissions perspective on energy efficiency: an empirical analysis of China's coastal areas. Appl Energy. 2017;185:604-14

30. Ruggieri M, Plaia A. An aggregate AQI: comparing different standardizations and introducing a variability index. Sci Total Environ. 2012:420:263-72.

31. Song M-L, Zhang L-L, Liu W, Fisher R. Bootstrap-DEA analysis of BRICS' energy efficiency based on small sample data. Appl Energy. 2013;112:1049-55.

32. Tone K, Tsutsui M. Dynamic DEA: a slacks-based measure approach Omega. 2010;38:145-56.

33. Wang Ke, Wei Y-M. China's regional industrial energy efficiency and carbon emissions abatement costs. Appl Energy. 2014;130:617-31.

34. Wang Ke, Wei Y-M, Zhang X. Energy and emissions efficiency patterns of Chinese regions: a multi-directional efficiency analysis. Appl Energy. 2013a; 104:105-16.

35. Wang QW, Zhou P, Shen N, Wang SS. Measuring carbon dioxide emission performance in Chinese provinces: a parametric approach. Renew Sustain Energy Rev. 2013b;21:324-30.

36. Wang Q, Zhang C, Cai W. Factor substitution and energy productivity fluctuation in China: a parametric decomposition analysis. Energy Policy. 2017;109:181-90

37. Wang S, Paul MJ, Dredze M. Social media as a sensor of air quality and public response in China. J Med Internet Res. 2015;17(3):22.

38. Wu J, Lin Lv, Sun J, Xiang Ji. A comprehensive analysis of China's regional energy saving and emission reduction efficiency: from production and treatment perspectives. Energy Policy. 2015;84:166-217.

39. Yao X, Guo C, Shao S, Jiang Z. Total-factor $\mathrm{CO}_{2}$ emission performance of China's provincial industrial sector: a meta-frontier non-radial Malmquist index approach. Appl Energy. 2016;184:1142-53.

40. Yeh T-L, Chen T-Y, Lai P-Y. A comparative study of energy utilization efficiency between Taiwan and China. Energy Policy. 2010;38(5):2386-94.

\section{Publisher's Note}

Springer Nature remains neutral with regard to jurisdictional claims in published maps and institutional affiliations.
Ready to submit your research? Choose BMC and benefit from:

- fast, convenient online submission

- thorough peer review by experienced researchers in your field

- rapid publication on acceptance

- support for research data, including large and complex data types

- gold Open Access which fosters wider collaboration and increased citations

- maximum visibility for your research: over 100M website views per year

At BMC, research is always in progress.

Learn more biomedcentral.com/submissions 